\title{
Reúso de água na irrigação de mudas de mamoeiro no Semiárido brasileiro
}

\section{Reuse of water in the irrigation of papaya seedlings in the Brazilian semiarid}

\author{
Diego Ernani Leite Bezerra ${ }^{1}$, Pedro Lima Filho ${ }^{2}$, Ednaldo Barbosa Pereira Júnior ${ }^{3}$, Patrícia Roque \\ Lemos Azevedo ${ }^{1}$, Edvanildo Andrade Silva ${ }^{1}$
}

${ }^{1}$ Mestrandos pelo Programa Pós-Graduação em Sistema Agroindustrial, Universidade Federal de Campina Grande, diegobezerra82@hotmail.com, patricia.roque@ifpb.edu.br, edvanildo@hotmail.com; ${ }^{2}$ Doutorando em Agronomia, Universidade Federal da Paraíba, Campus Areia, pslimaf@yahoo.com.br; ${ }^{3}$ Professor e Doutor no Instituto Federal da Paraíba, Campus Sousa, ebpjr2@ hotmail.com

\section{A R T I G O}

Recebido: $27 / 08 / 2018$

Aprovado: 04/12/2018

\section{Palavras-chave:}

Reutilização

Solo

Efluente

Key words:

Reuse

Soil

Effluent

\section{R E S U M O}

As precipitações pluviométricas irregulares e a elevada evapotranspiração são características da região semiárida do Nordeste Brasileiro. O conjunto dessas variáveis fazem da água um fator limitante para agricultura irrigada, o que torna a reutilização necessária, principalmente em locais sob condições de crescente escassez. Este trabalho foi realizado objetivando-se propor o aproveitamento de água de ar condicionado e efluente agroindustrial na produção e desenvolvimento de mudas de mamoeiro. A pesquisa foi desenvolvida no setor de produção de mudas localizado no Instituto Federal da Paraíba, Campus Sousa. Utilizou-se o delineamento de blocos inteiramente casualizados, com cinco tratamentos e quatro repetições. Os tratamentos foram o uso de água proveniente de poço artesiano, ar condicionado da combinação ar condicionado e poço artesiano (1:1), de efluente agroindustrial; da combinação efluente agroindustrial e ar condicionado (1:1). As mudas de mamão foram produzidas em sacos plásticos, utilizando Neossolo Flúvico e esterco na proporção $(2: 1)$ como substrato. Foram avaliadas as seguintes variáveis: altura de planta, diâmetro de caule, número de folhas, massa verde e seca da parte aérea e raiz, teor de (nitrogênio, fósforo e potássio) das folhas e influência nos atributos do solo $(\mathrm{pH}, \mathrm{P}, \mathrm{K}$, $\mathrm{Na}, \mathrm{Ca}, \mathrm{Mg}, \mathrm{MO}, \mathrm{PST}$ ). O uso da água de efluente agroindustrial inferiu menores resultados para maioria das variáveis. A utilização de águas ar condicionado surge como uma alternativa economicamente viável para a utilização na irrigação de mudas de mamoeiro.

\section{A B S T R A C T}

Irregular pluvimetric precipitations and high evapotranspiration are characteristic of the semiarid region of northeastern Brazil. The set of these variables make water a limiting factor for irrigated agriculture, which makes reuse necessary, especially in places under conditions of growing scarcity. The objective of this work was to propose the use of water from air conditioning and agroindustrial effluent in the production and development of papaya seedlings. The research was developed in the seedling production sector located at the Federal Institute of Paraíba, Campus Sousa. A completely randomized block design was used, with five treatments and four replications. The treatments were the use of water from artesian well, air conditioning of the combination air conditioning and artesian well (1:1), of agroindustrial effluent; Of the combination of agroindustrial effluent and air conditioning (1:1). Papaya seedlings were produced in plastic bags, using Neossol Fluvic and manure in proportion (2:1) as substrate. The following variables were evaluated: plant height, stem diameter, number of leaves, green and dry mass of shoots and roots, content of (nitrogen, phosphorus and potassium) of leaves and influence on soil attributes ( $\mathrm{PH}, \mathrm{P}, \mathrm{K}, \mathrm{Na}, \mathrm{Ca}, \mathrm{Mg}$, MO, PST). The use of water from agroindustrial effluent infered lower results for most variables. The use of air-conditioning waters emerges as an economically viable alternative for the use in irrigation of papaya seedlings.

\section{INTRODUÇÃO}

A fruticultura é um dos setores de maior importância para o agronegócio brasileiro, o país ocupa o terceiro lugar no ranking de maiores produtores de frutas do mundo, ficando atrás apenas de China e Índia, o que mostra sua relevância para a economia brasileira, com destaque para o mamão uma das frutas de maior produção no país (SEBRAE, 2015), a

\section{Revista Verde}

ISSN 1981-8203

Pombal, Paraíba, Brasil v. 14, n.1, jan.-mar, p.05-11, 2019 doi: 10.18378/rvads.v14i1.5942 
espécie Carica papaya L. é o mamoeiro mais cultivado em todo mundo.

A agricultura é uma atividade que sempre consumiu muita água. $\mathrm{O}$ aumento da população mundial exigiu a modernização das técnicas agrícolas, provocando um grande aumento no consumo de água e um crescente desequilíbrio ecológico. Dados da UNESCO 2016 (Organização das Nações Unidas para a Educação, a Ciência e a Cultura) apontam que aproximadamente $70 \%$ de toda a água potável disponível no mundo são utilizadas para irrigação, enquanto as atividades industriais consomem $20 \%$ e o uso doméstico $10 \%$.

As precipitações pluviométricas irregulares e a elevada evapotranspiração são características da região semiárida do Nordeste Brasileiro, essas variáveis fazem da água um fator limitante para várias atividades, dentre elas, a agricultura irrigada. Para minimizar este problema, uma estratégia vem sendo abordada em pesquisas, o uso de fontes alternativas de água, o aproveitamento agrícola de águas residuárias na produção de mudas, forragem, fruteiras e cafeeiras e um exemplo nos trabalhos de BATISTA et al., 2014; COSTA et al., 2014; SILVA et al., 2011; SOUZA et al., 2011.

Tem-se buscado métodos alternativos de reutilização da água, como o aproveitamento das águas pluviais, água-cinza, águas residuais tratadas e a dessalinização, que aparecem como meios de conservação da água e como alternativas para enfrentar a falta desse recurso, tanto para fins potáveis quanto não potáveis, tornando uma opção prática e a baixo custo para minimizar a escassez (PUSHARD, 2008).

Os aparelhos de ar condicionado promovem a geração de água resultante da condensação, essa água na maioria das vezes e desperdiçada para o solo ou para o esgoto. De acordo com Mota et al. (2012) em média um ar condicionado com 12 mil BTUs gera em torno de $300 \mathrm{ml}$ de água por hora, desta forma, que fica em média 12 horas com o ar ligado das $7 \mathrm{~h}$ às 19h serão 3,6 litros de água produzidos por este aparelho. Nóbrega et al. (2018) afirmam que a água de ar condicionado mostrou-se uma alternativa viável para a utilização na irrigação de mudas de goiaba.

Kummer et al. (2012) afirmam que a utilização de efluentes na agricultura cresceu consideravelmente nos últimos anos em muitos países, inclusive no Brasil; no entanto, ainda não foram suficientemente estudados todos os aspectos positivos e negativos dessa técnica, especialmente sobre as propriedades físicas e químicas do solo, absorção de nutrientes pelas plantas ou sua toxidez.

Desta forma, tornou-se necessário desenvolver este trabalho com intuito de aproveitar efluente agroindustrial, água do sistema de ar condicionado e sua combinação como forma de reuso e otimização da água bruta, visando sua viabilidade na produção e desenvolvimento de mudas de mamoeiro.

\section{MATERIAL E MÉTODOS}

O experimento foi instalado e conduzido no viveiro de mudas da Unidade São Gonçalo do Instituto Federal de Educação Ciência e Tecnologia da Paraíba, Campus - SousaPB, que fica localizado no Perímetro Irrigado de São Gonçalo zona fisiográfica do Sertão Paraibano a 220 metros de altitude, de coordenadas geográfica latitude $6^{\circ} 45^{\prime} 33^{\prime \prime}$ Sul e longitude $38^{\circ} 13^{\prime} 41^{\prime}$, no período de setembro de 2017 a janeiro de 2018.

A precipitação pluviométrica registrada no período do experimento na região do perímetro irrigado foi de $0 \mathrm{~mm}$, com uma temperatura mínima de $22^{\circ} \mathrm{C}$ e uma máxima de $38^{\circ}$ C (INMET) . A evaporação média anual é de 3.056,6 mm. O clima da região é do tipo Bsh da classificação de Köppen, semiárido quente (DNOCS). Para o desenvolvimento da pesquisa além do viveiro de mudas foram envolvidos também outros setores da escola fazenda.

O delineamento experimental utilizado foi de blocos inteiramente casualizados, com cinco tratamentos e quatro repetições. A parcela experimental foi composta por três plantas. Os tratamentos resultaram em $\mathrm{T} 1=100 \%$ Poço Artesiano (PA), T2 $=100 \%$ Ar Condicionado (AC), T3 = Combinação $50 \%$ Ar Condicionado $+50 \%$ Poço Artesiano (AC+PA), T4 = Combinação $50 \%$ Efluente Agroindustrial + $50 \%$ Ar Condicionado $(\mathrm{EA}+\mathrm{AC})$ e $\mathrm{T} 5=100 \%$ Efluente Agroindustrial (EA).

A coleta da água proveniente dos sistemas de ar condicionado foi feita no Bloco de Agroecologia localizado no Instituto Federal da Paraíba Campus Sousa, composto por 16 dependências climatizadas, com sistema de ar condicionado que variam na faixa de 12.000 a 24.000 BTUS, sendo sete, ficando ligados diariamente no horário de expediente (PERREIRA JUNIOR et al., 2018). O sistema de coleta de água compõe tubos de PVC de $20 \mathrm{~mm}$ conectados na saída de cada mangueira de dreno dos aparelhos e direcionados para uma caixa coletora de $500 \mathrm{~L}$.

O efluente Agroindustrial foi coletado no Bloco de Agroindústria e a coleta foi possível devido a um desvio, feito na tubulação de esgoto do setor de Processamento de Leite e Derivados, com destino a uma caixa coletora com capacidade de 5001 (FERREIRA NETO, et al., 2017). A coleta da água proveniente de poço foi feita em um poço artesiano localizado próximo ao Bloco de Agroindústria;

Durante a condução do experimento foram realizadas três coletas de amostras das águas utilizadas para a irrigação (dos tratamentos) para determinar a sua composição química, a primeira no início do tratamento, a segunda com 45 dias e a terceira com 90 dias após a semeadura (DAS). As análises foram feitas pelo Laboratório de Análises de Solo, Água e Planta do IFPB, Campus Sousa, cujo resultado encontra-se na (Tabela 1).

Tabela 1. Análise química das águas utilizadas para irrigação.

\begin{tabular}{|c|c|c|c|c|c|c|c|c|c|c|c|c|c|c|}
\hline Fonte & $\mathrm{pH}$ & $\begin{array}{c}\mathrm{CE} \\
\mathrm{Dsm}^{-1}\end{array}$ & K & $\mathrm{Na}$ & $\mathrm{Ca}$ & $\mathrm{Mg}$ & $\mathrm{SO}_{4}$ & $\begin{array}{l}\mathrm{CO}_{3}{ }^{2} \\
(\mathrm{mmol}\end{array}$ & $\begin{array}{l}\mathrm{HCO}_{3} \\
\mathrm{HCO}^{0,5} \\
----.\end{array}$ & $\mathrm{CL}^{--}$ & $\begin{array}{l}\text { CSR } \\
----\end{array}$ & $\begin{array}{l}\mathrm{NaCl} \\
-------1\end{array}$ & $\begin{array}{l}\mathrm{CaCO}_{3} \\
\mathrm{~g} \mathrm{~L}^{-1}---\end{array}$ & $\begin{array}{c}\mathrm{RAZ} \\
\left(\mathrm{mmol}_{\mathrm{c}}\right)\end{array}$ \\
\hline $\mathrm{PA}$ & 8,0 & 0,98 & 1,33 & 10,1 & 2,3 & 2,0 & 0,37 & 0,50 & 7,0 & 4,4 & 6,0 & 467 & 388 & 6,11 \\
\hline $\mathrm{AC}$ & 6,9 & 0,05 & 0,22 & 0,06 & 0,16 & 0,1 & 0,09 & 0,00 & 3,8 & 0,7 & 3,6 & 16,6 & 18,8 & 0,09 \\
\hline $\mathrm{AC}+\mathrm{PA}$ & 8,0 & 0,54 & 0,83 & 3,4 & 1,5 & 1,2 & 0,14 & 0,42 & 6,2 & 2,2 & 3,6 & 265 & 226 & 2,94 \\
\hline $\mathrm{EA}+\mathrm{AC}$ & 5,9 & 0,65 & 1,3 & 4,3 & 0,9 & 0,6 & 0,28 & 0,00 & 3,6 & 5,4 & 5,3 & 311 & 263 & 4,72 \\
\hline EA & 5,5 & 1,23 & 3,7 & 11,2 & 2,2 & 1,0 & 0,41 & 0,00 & 6,4 & 5,8 & 4,9 & 576 & 487 & 8,4 \\
\hline
\end{tabular}

$\mathrm{PA}=$ Poço Artesiano; $\mathrm{AC}=\mathrm{Ar}$ condicionado; $\mathrm{AC}+\mathrm{PA}=50 \% \mathrm{Ar}$ condicionado $+50 \%$ Poço Artesiano; $\mathrm{EA}+\mathrm{AC}=50 \%$

Efluente agroindustrial $+50 \%$ Ar condicionado; $\mathrm{EA}=$ Efluente agroindustrial. 
$\mathrm{Na}$ produção das mudas foram usadas como materiais propagativos sementes selecionadas de mamão papaya (Carica papaya L.) compradas no comércio da cidade de Sousa-PB. O substrato usado foi proveniente de um Neossolo Flúvico e esterco na proporção $(2: 1 \mathrm{v})$, condicionados em recipientes (sacos plásticos de $2 \mathrm{~L}$ ) preenchidos manualmente e conduzidos ao viveiro. Em seguida, foi coletada uma amostra do substrato para análise química feita pelo Laboratório de Análises de Solo, Água e Planta, do IFPB Campus Sousa - PB, cujo resultado encontra-se na (Tabela 2).

Tabela 2. Análise química do substrato preparado para o experimento.

\begin{tabular}{|c|c|c|c|c|c|c|c|c|c|c|c|}
\hline $\begin{array}{c}\mathrm{pH} \\
\mathrm{H}_{2} \mathrm{O}\end{array}$ & $\begin{array}{c}\mathrm{P} \\
\mathrm{mg} \mathrm{dm}\end{array}$ & $\mathrm{K}$ & NA & $\mathrm{Ca}$ & $\mathrm{Mg}$ & $\begin{array}{c}\mathrm{Al} \\
-\mathrm{Cmol}^{\mathrm{c}} \mathrm{dm}^{-3}\end{array}$ & $\mathrm{H}+\mathrm{Al}$ & SB & CTC & $\begin{array}{c}\mathrm{MO} \\
\mathrm{g} \mathrm{kg}^{-1}\end{array}$ & $\begin{array}{c}\text { PST } \\
\%\end{array}$ \\
\hline 7,6 & 1196 & 3,40 & 0,86 & 7,6 & 0,5 & 0,00 & 0,00 & 12,4 & 12,4 & 24,29 & 7 \\
\hline
\end{tabular}

Depois foi realizada a semeadura colocando-se três sementes por recipiente, na profundidade de $2 \mathrm{~cm}$, cobrindoas com fina camada de substrato e casca de arroz para conservar a umidade e favorecer a germinação, com posterior raleamento, deixando-se a plântula mais vigorosa e cortando as demais rentes ao substrato com auxílio de uma tesoura.

Durante a condução do experimento foram feitas irrigações diárias (manhã) manualmente, fornecendo um volume de água suficiente para elevar a umidade do substrato próximo à capacidade de campo. As plantas espontâneas foram eliminadas manualmente, assim que as mesmas surgiram. Durante o período de condução do experimento, não foi feita nenhuma adubação em cobertura.

Aos 30, 60 e 90 (DAS) foram avaliadas as características morfológicas: altura de plantas - AP (obtido pela distância entre a região do colo e a gema apical do ramo principal), diâmetro do caule - DC (obtido pela medição das plantas a oito centímetros acima do colo, com o auxílio de um paquímetro digital) e número de folhas - NF (obtido pela contagem total do número de folhas totalmente expandidas).

Na última avaliação aos 90 (DAS) foi determinada a massa fresca da parte aérea (MFA) e massa fresca da raiz (MFR), e massa seca da parte aérea (MSA) e da raiz (MSR) (obtida pela separação da raiz através de um corte na região do colo, acondicionadas em sacos de papel, etiquetadas e secadas em estufa a $65^{\circ} \mathrm{C}$, com circulação forçada de ar até peso constante).

Após o término do experimento foi coletado amostra composta do solo em cada parcela experimental para determinar o pH e os teores de Fósforo (P), Potássio (K), Sódio $(\mathrm{Na})$, cálcio $(\mathrm{Ca})$, Magnésio $(\mathrm{Mg})$, matéria orgânica (MO) e Porcentagem de sódio trocável (PST) do solo com o intuito de verificar as mudanças no solo durante o período experimental, analisada conforme a metodologia (EMBRAPA 1997) no laboratório de Solo, Água e Planta do IFPB, Campus Sousa.

O material vegetal seco foi triturado no moinho de facas willey e encaminhado ao laboratório para determinar os teores de nitrogênio que foi realizado conforme a metodologia de TEDESCO et al. (1995), para fósforo e potássio foi realizada conforme Malavolta et al. (1989).

Os resultados foram submetidos à Análise de Variância (ANOVA) e as médias, comparadas pelo teste de Tukey, a 0,05 de probabilidade, através do programa computacional SISVAR (FERREIRA, 2008).

\section{RESULTADOS E DISCUSSÃO}

Para altura de plantas observou-se na tabela 3 diferenças significativas entre alguns tratamentos testados aos 30, 60 e
90 (DAS). A maior diferença significativa para variável altura está entre os tratamentos T2 e T5, a variação entre eles aos 30 (DAS) ficou em 13,57cm, aos 60 (DAS) a variação aumentou para 15,20 cm e aos 90 (DAS) essa variação diminuiu para $11,75 \mathrm{~cm}$. A menor altura foi registrada no Tratamento T5 aos 90 (DAS) com $39,50 \mathrm{~cm}$ e a maior no Tratamento T2 com $51,25 \mathrm{~cm}$, resultado semelhante foi encontrado por Nobrega et al. (2017) com mudas de goiabeira irrigadas com diferentes tipos de água, o tratamento com água de ar condicionado teve desenvolvimento superior ao efluente agroindustrial na variável altura de planta.

Com mudas de mamoeiro, Pinheiro et al. (2017) constataram que plantas irrigadas com água de CEa de 3,5 dS $\mathrm{m}^{-1}$ sofreram reduções na altura da planta de $22,01 \% \mathrm{em}$ relação as plantas irrigadas com água de menor CEa $(0,3 \mathrm{dS}$ $\mathrm{m}^{-1}$ ), isso justifica a diferença significativa de altura de planta dos tratamentos T2 (irrigado com água com menor CEa entre todos os tratamentos) e T5 (irrigado com água com maior CEa entre todos os tratamentos), vide (tabela1), evidenciando que o mamoeiro tem crescimento afetado quando irrigado com água salina. A redução na altura da planta ocorre devido à água salina reduzir o potencial osmótico do solo, e consequentemente a energia livre da água, diminuindo a absorção de água pela planta e a turgescência das células, a qual afeta as taxas de elongação e divisão celular, que reflete diretamente no crescimento das plantas ocasionando esta redução (ASHRAF; HARRIS, 2004)

Tabela 3. Altura de plantas $(\mathrm{cm})$ de mudas de mamoeiro, irrigadas com diferentes tipos de água

Altura de Planta $(\mathrm{cm})$

----------------Após aplicação dos tratamentos ----------------

\begin{tabular}{cccc} 
Tratamentos & 30 & 60 & 90 \\
T1 & $16,76 \mathrm{ba}$ & $29,42 \mathrm{ba}$ & $44,62 \mathrm{ba}$ \\
T2 & $20,02 \mathrm{a}$ & $33,53 \mathrm{a}$ & $51,25 \mathrm{a}$ \\
T3 & $15 \mathrm{~b}$ & $27,01 \mathrm{ba}$ & $41,46 \mathrm{~b}$ \\
T4 & $8,97 \mathrm{c}$ & $25,43 \mathrm{cb}$ & $43,35 \mathrm{ba}$ \\
T5 & $6,45 \mathrm{c}$ & $18,33 \mathrm{c}$ & $39,50 \mathrm{~b}$ \\
\hline CV \% & 12,27 & 12,53 & 9,69 \\
\hline
\end{tabular}

$\mathrm{T} 1=$ Poço Artesiano; $\mathrm{T} 2=\mathrm{Ar}$ condicionado; $\mathrm{T} 3=50 \% \mathrm{Ar}$ condicionado + $50 \%$ Poço Artesiano; $\mathrm{T} 4=50 \%$ Efluente agroindustrial $+50 \% \mathrm{Ar}$ condicionado; T5= Efluente agroindustrial. Médias seguidas, em linha, com letras diferentes letras apresentaram efeitos significativo a nível de $(\mathrm{p}<0,050)$ pelo teste Tukey.

Os Tratamentos T1 e T2 demostraram os melhores comportamentos para variável diâmetro de caule, já o Tratamento T5 têm as médias mais baixas tabela 4, resultado semelhante foram encontrado por Nóbrega et al. (2018) com mudas de goiabeira irrigadas com diferentes tipos de água, o tratamento com água de ar condicionado teve resultado muito 
superior ao efluente agroindustrial. Em seu trabalho analisando fontes e níveis de salinidade em mudas de mamoeiro Cavalcante et al. (2010) detectaram que o crescimento em altura e o diâmetro do caule das plantas foram prejudicados com o aumento da condutividade elétrica da água de irrigação.

Tabela 4. Diâmetro do caule de mudas de mamoeiro, irrigadas com diferentes tipos de água.

Diâmetro do Caule (mm)

-Após aplicação dos tratamentos ---------------

\begin{tabular}{cccc}
\hline Tratamentos & 30 & 60 & 90 \\
\hline T1 & $5,93 \mathrm{a}$ & $11,96 \mathrm{a}$ & $14,09 \mathrm{a}$ \\
T2 & $6,25 \mathrm{a}$ & $11,39 \mathrm{ba}$ & $14,45 \mathrm{a}$ \\
T3 & $5,55 \mathrm{a}$ & $9,92 \mathrm{cb}$ & $12,87 \mathrm{a}$ \\
T4 & $3,48 \mathrm{~b}$ & $8,96 \mathrm{c}$ & $13,25 \mathrm{a}$ \\
T5 & $2,36 \mathrm{c}$ & $6,90 \mathrm{~d}$ & $12,45 \mathrm{a}$ \\
\hline CV \% & 7,29 & 6,91 & 6,84 \\
\hline
\end{tabular}

$\mathrm{T} 1=$ Poço Artesiano; $\mathrm{T} 2=\mathrm{Ar}$ condicionado; $\mathrm{T} 3=50 \% \mathrm{Ar}$ condicionado + $50 \%$ Poço Artesiano; $\mathrm{T} 4=50 \%$ Efluente agroindustrial $+50 \% \mathrm{Ar}$ condicionado; T5= Efluente agroindustrial. Médias seguidas, em linha, com letras diferentes apresentaram efeitos significativo a nível de $(\mathrm{p}<0,050)$ pelo teste Tukey.

Aos 30 (DAS) para variável número de folhas (NF) os Tratamentos T1, T2 e T3 não tiveram diferença entre si, enquanto que nos tratamentos T4 e T5 ocorreu o decréscimo no número de folhas (tabela 5). Aos 60 (DAS), percebe-se um comportamento semelhante nos tratamentos T1, T2 e T5 sendo o maior valor obtido irrigado com o Tratamento T4. Aos 90 (DAS) o Tratamento T5 apesar de apresentar o maior CEa bem acima dos demais tratamentos tabela 1, refletiu numa maior quantidade de folhas comparado com demais tratamentos. Trabalho com comportamento semelhante foram verificados por Pinheiro et al. (2017) que observaram que houve efeito significativo dos níveis de salinidade da água de irrigação sobre o número de folhas, o aumento da salinidade da água de irrigação afetou positivamente o NF de mudas de mamoeiro, as plantas que foram submetidas a irrigação com CEa de 3,5 dS m ${ }^{-1}$ apresentaram acréscimos de 6,94\% em comparação com o menor nível salino (CEa 0,3 $\mathrm{dS} \mathrm{m}^{-1}$ ).

Tabela 5. Numero de Folhas de mudas de mamoeiro, irrigadas com diferentes tipos de água.

\section{Número de Folhas}

Após aplicação dos tratamentos ---------------

\begin{tabular}{cccc}
\hline Tratamentos & 30 & 60 & 90 \\
\hline T1 & $13 \mathrm{a}$ & $14 \mathrm{ba}$ & $14 \mathrm{~b}$ \\
T2 & $13 \mathrm{a}$ & $13 \mathrm{ba}$ & $12 \mathrm{~b}$ \\
T3 & $12 \mathrm{a}$ & $12 \mathrm{~b}$ & $13 \mathrm{~b}$ \\
T4 & $09 \mathrm{~b}$ & $15 \mathrm{a}$ & $14 \mathrm{~b}$ \\
T5 & $07 \mathrm{c}$ & $13 \mathrm{ba}$ & $17 \mathrm{a}$ \\
\hline CV \% & 6,02 & 8,51 & 7,73 \\
\hline
\end{tabular}

T1= Poço Artesiano; $\mathrm{T} 2=$ Ar condicionado; $\mathrm{T} 3=50 \% \mathrm{Ar}$ condicionado + $50 \%$ Poço Artesiano; T4 $=50 \%$ Efluente agroindustrial $+50 \% \mathrm{Ar}$ condicionado; T5= Efluente agroindustrial. Médias seguidas, em linha, com letras diferentes apresentaram efeitos significativo a nível de $(\mathrm{p}<0,050)$ pelo teste Tukey.

Os resultados da Massa Fresca da parte aérea (MFA) e Massa Fresca da raiz (MFR) diferiram estatisticamente $(\mathrm{p}<0,05)$ entre si pelo teste de Tukey entre os tratamentos, evidenciando que a cultura do mamão respondeu de forma significativa aos tipos de água conforme os resultados exposto na Tabela 6.

A maior média (MFA) com 210,09 $\mathrm{g}_{\text {planta }}{ }^{-1}$ foi obtida no Tratamento T1, a menor média no T5 com 80,50 $\mathrm{g}_{\text {planta }}{ }^{-}$ 1 , houve uma variação significativa entre os dois tratamentos de $129,59 \mathrm{~g}$ planta $^{-1}$. O tratamento com maior média para (MFR) com 125,16 g planta ${ }^{-1}$ foi T2, o de menor média entre os tratamentos com $83,67 \mathrm{~g}_{\text {planta }}{ }^{-1}$ foi o $\mathrm{T} 5$, a variação entre o de maior e menor média ficou em $41,49 \mathrm{~g}$ planta $^{-1}$.

O tratamento com maior média para Massa Seca parte aérea (MSA) com 25,06 $\mathrm{g} \mathrm{planta}^{-1}$ foi T2, o que apresentou à menor média com $8,17 \mathrm{~g}_{\text {planta }^{-1}}$ foi $\mathrm{T} 5$, entre os dois tratamentos a variação foi de $16,89 \mathrm{~g}$ planta $^{-1}$, a água utilizada na irrigação do T5 apresenta o maior CEa dentre todos os tratamentos, isso influenciou de forma negativa a produção de fitomassa da parte aérea dessas plantas cultivadas com esse tipo de água . Pinheiro et. al (2017) observaram que aumento da CEa afetou de forma negativa a fitomassa seca de caule de mudas de mamoeiro, houve uma redução de $22,4 \%$ das plantas irrigadas com água de $3,5 \mathrm{dS} \mathrm{m}^{-1}$ quando comparado com as do menor nível salino $\left(0,3 \mathrm{dS} \mathrm{m}^{-1}\right)$. A redução na produção na biomassa é consequência de mecanismos de ajustamento às condições de estresse salino a qual a cultura esta submetida, incluindo modificações no balanço iônico, potencial hídrico, nutrição mineral, fechamento estomático, eficiência fotossintética e alocação de carbono (TAIZ et al., 2013).

Tabela 6. Massa fresca e seca da parte aérea e raiz de mudas de mamoeiro, aos 90 dias irrigados com diferentes tipos de água.

\begin{tabular}{ccccc} 
Tratamentos & \multicolumn{2}{c}{ Massa Fresca } & \multicolumn{2}{c}{ Massa Seca } \\
\cline { 2 - 5 } & Aérea & Raiz & Aérea & Raiz \\
\hline T1 & $210,09 \mathrm{a}$ & $109,46 \mathrm{~b}$ & $21,76 \mathrm{~b}$ & $11,50 \mathrm{cb}$ \\
T2 & $209,40 \mathrm{a}$ & $125,16 \mathrm{a}$ & $25,06 \mathrm{a}$ & $14,26 \mathrm{a}$ \\
T3 & $161,34 \mathrm{~b}$ & $100,49 \mathrm{~b}$ & $15,86 \mathrm{~d}$ & $12,82 \mathrm{ba}$ \\
T4 & $149,71 \mathrm{c}$ & $95,76 \mathrm{cb}$ & $18,36 \mathrm{c}$ & $9,61 \mathrm{c}$ \\
T5 & $80,50 \mathrm{~d}$ & $83,67 \mathrm{c}$ & $8,17 \mathrm{e}$ & $10,81 \mathrm{cb}$ \\
\hline CV \% & 2,57 & 6,63 & 5,49 & 8,9 \\
\hline
\end{tabular}

T1= Poço Artesiano; T2 = Ar condicionado; T3 = 50\% Ar condicionado + $50 \%$ Poço Artesiano; T4 $=50 \%$ Efluente agroindustrial $+50 \% \mathrm{Ar}$ condicionado; T5= Efluente agroindustrial. Médias seguidas, em linha, com letras diferentes apresentaram efeitos significativo a nível de $(\mathrm{p}<0,05)$ pelo teste Tukey.

Na tabela 6 a maior média para Massa Seca raiz (MSR) com 14,26 g planta $^{-1}$ foi obtida no Tratamento T2, a menor média foi obtida no T4, a variação entre os dois tratamentos ficou em 4,65 $\mathrm{g} \mathrm{planta}^{-1}$. Ao analisar o efeito de fontes e níveis de salinidade da água de irrigação sobre a emergência de plântulas e desenvolvimento vegetativo de mudas de mamoeiro Cavalcante et al. (2010) constataram que a biomassa seca das raízes e parte aérea foram expressivamente prejudicadas com aumento do teor salino das águas, expresso pela condutividade elétrica.

As mudas de mamoeiro irrigadas com os Tratamentos $\mathrm{T} 4$ (50\% Efluente agroindustrial $+50 \%$ Ar condicionado) e T5 (Efluente agroindustrial) inferiram os menores resultados. Tal resultado pode estar atribuído à baixa qualidade do efluente agroindustrial constatado pelo resultado da análise, principalmente pelos teores da $\mathrm{CE}, \mathrm{Na}, \mathrm{Cl}$ e a RAS (Tabela 1) da água utilizada na irrigação. Para Arruda et al. (2002), o excesso de sais na zona radicular causam, em geral, efeito deletério sobre as plantas, que se manifesta por redução na 
absorção de água, na taxa de fotossíntese e, consequentemente, no crescimento das plantas. Além disso, salienta-se que o efeito tóxico dos sais absorvidos pelas plantas, principalmente $\mathrm{Na}+\mathrm{e} \mathrm{Cl}-$ e a baixa capacidade de ajustamento osmótico das plantas à salinidade, também possam ter contribuído com a redução da velocidade de crescimento das plantas.

Houve diferença significativa $(\mathrm{p}<0,05)$ para o $\mathrm{pH}$, Porcentagem de Sódio Trocável (PST) e os teores de Potássio (K) e Sódio $(\mathrm{Na})$, ao contrário das variáveis, os teores de Matéria Orgânica (MO), Fósforo (P), cálcio (Ca) e Magnésio ( $\mathrm{Mg}$ ) não demostraram efeito de significância (tabela 7).

$\mathrm{O}$ pH do solo, apesar de demonstrar significância entre os tratamentos permaneceram alcalinos, o tratamento (T1) foi o que mais elevou o $\mathrm{pH}$ do solo, tal comportamento pode ser atribuído ao $\mathrm{pH}$, sódio da água de irrigação utilizada neste tratamento (Tabela 1). Considera-se adequado para água de irrigação um pH entre 6,5 e 8,4; fora dessa faixa, favorece o desequilíbrio nutricional das culturas irrigadas (AYERS; WESTCOT, 1991).

Observa-se na tabela 7 que os teores de $\mathrm{P}, \mathrm{Ca}^{+2} \mathrm{e} \mathrm{Mg}^{+2}$ no solo não tiveram diferença significava entre os tratamentos observados, permaneceram com concentração muita alta $\left(\mathrm{Ca}^{+2} \mathrm{e} \mathrm{Mg}^{+2}\right)$ e baixa (P).

Previa-se que o solo irrigado com os tratamentos T1 e T5 expressa-se maiores teores de Cálcio e Magnésio e um menor com o T2, o que não aconteceu, uma vez que a concentração desses cátions apresentam de forma diferenciada (tabela 1).

Comportamento semelhante foi observado por Sousa et al. (2006) referentes as concentrações de Fósforo, Cálcio e Magnésio avaliando o reuso de água residuária na produção de pimenta e nas características químicas do solo após o término do experimento localizada no município de Lagoa Seca, PB.

Nota-se na tabela 7 que ocorreu variação entre os tratamentos para os teores de $\mathrm{K}+$ no solo, apresentando diferença significativa $(p<0,05)$ entre os tratamentos. Os tratamentos T1, T2 e T3 apresentaram os maiores teores de $\mathrm{K}+$, diferindo dos demais os Tratamentos T4 e T5 apresentaram teores menores. É bom salientar que os tratamentos $\mathrm{T} 4$ e $\mathrm{T} 5$ permaneceram com concentrações altas de $\mathrm{K}+$ até o final do experimento, proveniente ainda dos altos teores desse elemento remanescente no substrato manipulado e utilizado no experimento (tabela 2) e dos altos valores de matéria orgânica (tabela 7). Diferentemente encontrado nesse trabalho, Duarte et al. (2008) verificando o efeito do reuso de efluente tratado no solo concluíram que não provocou alterações significativas no $\mathrm{pH}$, nem nos teores de fósforo e potássio do solo.

Ferreira Neto et al. (2013) avaliando alterações química no solo e produção de beterraba irrigada com água residuária constataram baixa concentração de potássio na água residuária utilizada no experimento, o que contribuiu, em parte, para não influenciar no aumento de potássio no solo.

Ainda na tabela 7, os teores de Sódio tiveram diferença significativa entre os tratamentos, os maiores teores de Sódio no solo foram expressos pelos tratamentos $\mathrm{T} 1$ e T5 plantas irrigadas pela agua do poço e efluente agroindustrial, respectivamente, o menor teor foi observado tratamento $\mathrm{T} 2$ que foi plantas irrigadas com água de ar condicionado, esse comportamento do solo é justificável pelas análises feitas nas águas utilizadas nos tratamentos, vindo a interferir na composição do solo (Tabela 1). Verificam-se também efeito significativo para o percentual de Sódio Trocável (PST).

Os trabalhos de Herpin et al. (2007) e Leal et al. (2009) também constataram aumento nos teores de $\mathrm{Na}$ no solo quando utilizaram efluente tratado de origem doméstica, atribuindo esse acúmulo ao fato do teor desse elemento no efluente ser elevado.

Percebe-se na tabela7, que os maiores teores de sódio nos tratamentos T1, T4 e T5 favoreceram a elevação da PST no solo. É bom salientar que o Tratamento T2 é único a ser considerado, segundo a classificação, como sendo sem problemas para cultivo das maiores das culturas ficando dentro da faixa (0-7), esse comportamento é visível devido às baixas concentrações de sódio no tratamento T2, irrigado com água do ar condicionado, constatado através nas análises nas tabela 1. Os demais tratamentos ficaram na faixa de pouco prejudicial.

Tabela 7. Características químicas do solo após o término do experimento, irrigados com diferentes tipos de águas.

\begin{tabular}{|c|c|c|c|c|c|}
\hline \multirow{2}{*}{$\begin{array}{l}\text { Características químicas } \\
\text { (fertilidade do solo) }\end{array}$} & \multicolumn{5}{|c|}{ Tratamentos } \\
\hline & $\mathrm{T} 1$ & $\mathrm{~T} 2$ & $\mathrm{~T} 3$ & $\mathrm{~T} 4$ & T5 \\
\hline $\mathrm{pH}$ & $8,6 \mathrm{a}$ & 8,4 ba & 8,37 ba & 8,37 ba & $8,27 \mathrm{~b}$ \\
\hline Fósforo $\left(\mathrm{mg} \mathrm{dm}^{-3}\right)$ & $1,36 \mathrm{a}$ & $1,44 \mathrm{a}$ & $1,42 \mathrm{a}$ & $1,32 \mathrm{a}$ & $1,40 \mathrm{a}$ \\
\hline Potássio $\left(\mathrm{cmol}_{\mathrm{c}} \mathrm{dm}^{-3}\right)$ & $2,45 \mathrm{a}$ & $2,64 \mathrm{a}$ & $2,73 \mathrm{a}$ & 2,16 ba & $1,60 \mathrm{~b}$ \\
\hline Sódio $\left(\mathrm{cmol}_{\mathrm{c}} \mathrm{dm}^{-3}\right)$ & $1,61 \mathrm{a}$ & $0,42 \mathrm{c}$ & $1,02 \mathrm{~b}$ & $1,30 \mathrm{ba}$ & 1,35 ba \\
\hline Cálcio $\left(\mathrm{cmol}_{\mathrm{c}} \mathrm{dm}^{-3}\right)$ & $6,0 \mathrm{a}$ & $6,75 \mathrm{a}$ & $6,65 \mathrm{a}$ & $6,05 \mathrm{a}$ & $7,05 \mathrm{a}$ \\
\hline Magnésio $\left(\mathrm{cmol}_{\mathrm{c}} \mathrm{dm}^{-3}\right)$ & $1,50 \mathrm{a}$ & $1,45 \mathrm{a}$ & $1,40 \mathrm{a}$ & $1,80 \mathrm{a}$ & $2,05 \mathrm{a}$ \\
\hline Soma da base $\left(\mathrm{cmol}_{c} \mathrm{dm}^{-3}\right)$ & $11,56 \mathrm{a}$ & $11,26 \mathrm{a}$ & $11,81 \mathrm{a}$ & $11,32 \mathrm{a}$ & $12,05 \mathrm{a}$ \\
\hline $\mathrm{CTC}\left(\mathrm{cmol}_{\mathrm{c}} \mathrm{dm}^{-3}\right)$ & $11,56 \mathrm{a}$ & $11,26 \mathrm{a}$ & $11,81 \mathrm{a}$ & $11,32 \mathrm{a}$ & $12,05 \mathrm{a}$ \\
\hline Material Orgânico $\left(\mathrm{g} \mathrm{kg}^{-1}\right)$ & $33,95 \mathrm{a}$ & $35,64 \mathrm{a}$ & $30,87 \mathrm{a}$ & $33,24 \mathrm{a}$ & $31,64 \mathrm{a}$ \\
\hline PST \% & $13,7 \mathrm{a}$ & $3,7 \mathrm{~d}$ & $8,7 \mathrm{c}$ & $11,5 \mathrm{~b}$ & $11 \mathrm{~b}$ \\
\hline
\end{tabular}

T1= Poço Artesiano; T2= Ar condicionado; T3 = 50\% Ar condicionado + 50\% Poço Artesiano; T4 = 50\% Efluente agroindustrial + 50\% Ar condicionado; T5= Efluente agroindustrial.

Segundo os dados dispostos na tabela 7, observa-se que o conteúdo de matéria orgânica existente no solo irrigado não apresentou diferença significativa entre os diferentes tratamentos. Permanecendo com concentrações muita alta. A Matéria Orgânica do solo (MO) é fonte de energia para os microrganismos, aumenta a capacidade de armazenar umidade, reter e fixar Fósforo e Nitrogênio, aumentar a capacidade de troca de cátions (CTC), ajudar a segurar Potássio, Cálcio e Magnésio, entre outros nutrientes disponíveis para as raízes da planta (PRIMAVESI, 2002). 
A análise de variância dos resultados obtidos (tabela 8) evidencia efeito significativo $(\mathrm{p}<0,05)$ para variáveis teores de Fósforo (P) e Potássio (K), exceto para os teores de $\mathrm{N}$ na planta.

Os teores de Nitrogênio $(\mathrm{N})$ de todos os tratamentos encontram-se abaixo da faixa de 45 a $50 \mathrm{~g} \mathrm{~kg}^{-1}$ descrita como ideal por Malavolta et al. (1997) para a cultura do mamão. Evidenciando que as irrigações com os diferentes tratamentos não contribuíram para o acúmulo desse elemento na planta.

Segundo Péres-Alfocea et al. (1993) o efeito da salinidade sobre o teor de $\mathrm{N}$ parece depender do nível de salinidade, da duração em que a planta é submetida ao estresse salino e, de maior importância, dos diferentes graus de tolerância entre espécies ou genótipos. Um grande número de estudo indica que a absorção ou acúmulo de $\mathrm{N}$ na parte aérea das plantas pode ser reduzido pela salinidade (PATEL et al., 2010)

Os teores de Fósforo (P) dos tratamentos T2, T3, T4 e T5 estão bem acima da faixa de 5-7 $\mathrm{g} \mathrm{kg}^{-1}$ descrita como ideal por Malavolta et al. (1997), apenas T1 foi o único que ficou na faixa tida como ideal para cultura do mamão, enquanto que os teores de Potássio (K) dos tratamentos T1, T2, T3 e T4 estão bem acima da faixa de $25-30 \mathrm{~g} \mathrm{~kg}^{-1}$ descrita como ideal por Malavolta et al. (1997), o tratamento T5 foi o único que ficou na faixa tida como ideal para cultura do mamão (tabela $8)$.

Tabela 8. Teores de $\mathrm{N}, \mathrm{P}$ e $\mathrm{K}$ em mudas de mamoeiro irrigado com diferentes tipos de águas.

Teores Foliares

\begin{tabular}{|c|c|c|c|}
\hline Tratamentos & $\mathrm{N}$ & $\mathrm{P}$ & $\mathrm{K}$ \\
\hline $\mathrm{T} 1$ & $40,20 \mathrm{a}$ & $6,47 \mathrm{c}$ & $45,51 \mathrm{a}$ \\
\hline $\mathrm{T} 2$ & 38,19 a & $9,69 \mathrm{~b}$ & $46,27 \mathrm{a}$ \\
\hline T3 & $41,08 \mathrm{a}$ & $8,41 \mathrm{cb}$ & $46,95 \mathrm{a}$ \\
\hline $\mathrm{T} 4$ & $39,37 \mathrm{a}$ & $10,34 \mathrm{~b}$ & $37,19 b$ \\
\hline $\mathrm{T} 5$ & $37,41 \mathrm{a}$ & $13,60 \mathrm{a}$ & $29,90 \mathrm{c}$ \\
\hline $\mathrm{CV} \%$ & 9,49 & 11,55 & 7,85 \\
\hline
\end{tabular}

$\mathrm{T} 1=$ Poço Artesiano; $\mathrm{T} 2=\mathrm{Ar}$ condicionado; $\mathrm{T} 3=50 \% \mathrm{Ar}$ condicionado + $50 \%$ Poço Artesiano; T4 $=50 \%$ Efluente agroindustrial $+50 \% \mathrm{Ar}$ condicionado; T5= Efluente agroindustrial. Médias seguidas, em linha, com letras diferentes apresentaram efeitos significativo a nível de $(\mathrm{p}<0,050)$ pelo teste Tukey.

Ainda analisando a tabela 8 , percebe-se os teores crescente de $\mathrm{P}$ e decrescente de $\mathrm{K}$ apresentaram comportamento inverso nos diferentes tratamentos, mesmo com concentrações de $\mathrm{K}$ mais elevada no $\mathrm{T} 5$ comparado com os demais, constatado na análise dos tratamentos (tabela 1) não induziram na concentração foliar desse elemento. Portanto, é possível perceber que a salinidade da água expressada pela condutividade elétrica (CE) na (tabela 1) não limitou a absorção de $\mathrm{P}$ e $\mathrm{K}$ ao ponto de comprometer a adequação nutricional durante o período experimental.

Analisando indicadores nutricionais do mamoeiro Marinho et al. (2002) verificaram que o aumento nos teores de $\mathrm{P}$, no pecíolo, foi acompanhado por reduções nos teores de $\mathrm{N}$. Da mesma forma, reduções nos teores de $\mathrm{P}$ foram acompanhadas por aumentos nos teores de N. Esse mesmo autor, não observou deficiência de $\mathrm{K}$ pela análise foliares no mamoeiro.

\section{CONCLUSÕES}

A água de ar condicionado é uma alternativa viável para a utilização na irrigação de plântulas de mamoeiro.

O efluente agroindustrial não é recomendável para irrigação de plântulas de mamoeiro em virtude dos elevados teores de sódio e cloreto.

Os teores de nitrogênio $(\mathrm{N})$ nas mudas não foram afetados pelos diferentes tipos de águas utilizadas na irrigação, exceto os teores de fósforo $(\mathrm{P})$ e potássio $(\mathrm{K})$.

\section{REFERÊNCIAS}

ARRUDA, F. P.; ANDRADE, A. P.; SILVA, I. F.; PEREIRA, I. E.; GUIMARÃES, M. A. M. Efeito do estresse hídrico na emissão/abscisão de estruturas reprodutivas do algodoeiro herbáceo cv. CNPA 7H. Revista Brasileira de Engenharia Agrícola e Ambiental, v. 6, n. 1, p. 21-27, 2002.

ASHRAF M.; HARRIS, P. J. C. Potential biochemical indicators of salinity tolerance in plants. Plant Science, v.166, n.1, p.3-16, 2004.

AYERS, R. S.; Westcoot, D. W. A qualidade de água na agricultura. Campina Grande: UFPB, 1991, 218p.

BATISTA, R. O; MARTINEZ M. A; PAIVA, H. N.; BATISTA, R. O.; CECON, P. R. O efeito da água residuária da suinocultura no desenvolvimento e qualidade de mudas de Eucalyptus urophylla.Ciência Florestal, v. 24, n. 1, p. 127135, 2014.

CAVALCANTE, L. F.; CORDEIRO, J. C.; NACIMENTO, J. A. M.; CAVALCANTE, I. H. L.; DIAS, T. A. Fontes e níveis da salinidade da água na formação de mudas de mamoeiro cv. Sunrise solo. Semina: Ciências Agrárias, v. 31, suplemento 1, p. 1281-1290, 2010 .

COSTA, F. G. B. Desenvolvimento inicial de cultivares de melão fertirrigadas com distintas proporções de esgoto doméstico em Mossoró-RN. Revista Caatinga, v. 27, n. 2, p. $116-123,2014$

DNOCS, DEPARTAMENTO NACIONAL DE OBRAS CONTRA AS SECAS. Perímetro irrigado de São Gonçalo. Disponível:

<http://www.dnocs.gov.br/ dnocs/doc/canais/perimetros_irri gados/pb/sao_gon alo.htm> Acesso em: 17/04/2018.

DUARTE, A. S. R.; AIROLDI, P. S.; FOLEGATTI, M. V.; BOTREL, T. A.; SOARES, T. M. Efeitos da aplicação de efluente tratado no solo: $\mathrm{pH}$, matéria orgânica, fósforo e potássio. R. Bras. Eng. Agríc. Ambiental, v.12, n.3, p.302310, 2008.

EMBRAPA, Empresa Brasileira de Pesquisa Agropecuária, Manual de métodos de análise de solo, Centro Nacional de Pesquisa de Solos, $2^{\text {a }}$ ed. Rev. atual, Rio de Janeiro, 1997.

FERREIRA, D. F. Sisvar: um programa para análises e ensino estatístico. Revista Científica Symposium, v. 6, n. 2, p. 36-41, 2008. 
INMET, INSTITUTO NACIONAL DE METEREOLOGIA. Estação Metrológica de Observação de Superfície Automática. Disponível: <http://www.inmet.gov.br/portal/index.php?r=estacoes/estaco esautomaticas.> Acesso em: 10/08/2018.

HERPIN, U.; GLOAGUEN, T.V.; FONSECA, A.F.; MONTES,C.R.; MENDONÇA, F.C.; PIVELI, R.P.; BREULMANN,G.; FORTI, M.C. \& MELFI, A.J. Chemical effects on the soil-plant system in a secondary treated waste water irrigated coffee plantation - A pilot field study in Brazil. Agric. Water Manag, v. 89, p.105-115, 2007.

KUMMER, A. C. B.; SILVA, I. P. F.; LOBO, T. F.; GRASSI FILHO, H. Qualidade da água residuária para irrigação do trigo. In: IV WORKSHOP INTERNACIONAL DE INOVAÇÕES TECNOLÓGICAS NA IRRIGAÇÃO E I INOVAGRI INTERNATIONAL MEETING, Fortaleza, Anais... Fortaleza, 2012.

LEAL, R. M. P.; HERPIN, U.; FONSECA, A. F.; FIRME, L. P.;MONTES, C. R.; MELFI, A. J. Sodicity and salinity in a Brazilian Oxisol cultivated with sugarcane irrigated with waste water. Agric. Water Manag, v. 96, p. 307-316, 2009.

MALAVOLTA, E.; VITTI, G. C.; OLIVEIRA, S. A. Avaliação do estado nutricional das plantas: Princípios e aplicações. Piracicaba: POTAFOS, 1989. 201 p.

MALAVOLTA, E., VITTI, G. C., OLIVEIRA, S. A. Avaliação do estado nutricional das plantas: princípios e aplicações. Potafos, Piracicaba, Brasil. 1997, 281 p.

MARINHO C. S.; MONNERAT. P. H.; ALMY, J. R. CARVALHO, C.; MARINS, S. L. D. ; VIEIRA, A. Análise química do pecíolo e limbo foliar como indicadora do estado nutricional dos mamoeiros 'solo' e 'formosa. Scientia Agricola, v.59, n.2, p.373-381, 2002.

MOTA, T. R.; OLIVEIRA, D. M.; INADA, P. Utilização da água do sistema de ar condicionado visando o desenvolvimento sustentável. $10^{\circ}$ Forum de Extensão e cultura da UEM, 2012.

FERREIRA NETO, J.; DE QUEIRÓS M. M. F., NOBRE, R. G., PEREIRA JUNIOR, E. B., SOUSA, J. C.; SOUSA, J. $X$. Caracterização físico-química e microbiológica da beterraba irrigada com efluente agroindustrial. Rev. de Agroecologia no Semiárido, v. 1, n.1, p.13 - 23, 2017.

NÓBREGA, E. P.; SARMENTO, M. I. A.; RODRIGUES, M. L. M.; OLIVEIRA, P. R. R.; NETO, J. F.; MARACAJÁ, P. Desenvolvimento inicial de mudas de goiabeira irrigadas com diferentes tipos de água. Revista de agroecolgia no Semiárido, [S.1.], v. 1, n. 2, p. 01-09, 2018.

PATEL, A. D.; PANCHAL, N. S.; PANDEY, I. B.; PANDEY, A. N. Growth, water status and nutrien accumulation of seedlings of jatrophcurcas in response to soil salinity. Anales de Biología, v. 32, p. 59 - 71, 2010.

PEREIRA JUNIOR, E. B.; SOUSA, J. F.; LIMA, C. J.; HAFLE, O. M.; GOMES, D. J.; OLIVEIRA, F. T. Quantidade e qualidade da água dos aparelhos condicionadores de ar no IFPB Campus Sousa, PB. Revista de Agroecologia no Semiárido, v. 1, n. 1, p. 1-12, 2018.

PÉREZ-ALFOCEA, F.; ESTAÑCIA, M. T.; SANTA CRUZ, A.; BOLARIN, M. C. Effets of salinity on nitrate, total nitrogean, soluble protein and free amino acid levels in tomato plants. Journal Horticulture Science, v. 68, n. 4, p. $1021-1027,1993$.

PINHEIRO, F. W. A.; NOBRE, R. G.; SOUZA, L. P.; OLIVEIRA, S. G.; ARAÚJO, J. E. S.; VELOSO, L. L. S. A. Irrigação com águas salinas e adubação nitrogenada na produção de mudas de mamoeiro "Formosa". Revista Verde de Agroecologia e Desenvolvimento Sustentável, v.12, n. 1, p. 17-22, 2017.

PRIMAVESI, A. Agricultura em regiões tropicais. Manejo ecológicodo solo. São Paulo: Nobel. 2002. 549p.

PUSHARD, T. S. The State of Rainwater Harvesting In The U.S. On Tap , pp. 20-22, 2008.

SEBRAE, Serviço Brasileiro de Apoio às Micro E Pequenas Empresas - Boletim De Inteligencia. Agronegócio Fruticultura, 2015.2 Disponível em: <http://www.sebraemercados.com.br/wpcontent/uploads/2015/11/Panorama-do-mercado-defruticultura-no-Brasil.pdf .> Acesso em 15/05/2018.

SOUSA, J. T.; CEBALlOS, B. S. O; HENRIQUE, I. N.; DANTAS, J. P.; LIMA, S. M. Reuso de água residuária na produção de pimentão (Capsicum annuum L.). R. Bras. Eng. Agríc. Ambiental, v.10, n.1, p.89-96, 2006.

SOUZA, J. A. A.; BATISTA, R. O.; RAMOS, M. M.; SOARES, A. A. Contaminação microbiológica do perfil do solo com esgoto sanitário. Acta Scientiarum.Technology, v. 33, n. 1, p. 5-8, 2011.

TEDESCO, M. J.; GIANELLO, C.; BISSANI, C. A.; HOHNEN, H.; VOLKWEISS, S. J.; Análise de solo, plantas e outros materiais. Departamento de solos Faculdade de Agronomia Universidade Federal do Rio Grande do Sul, Porto Alegre, 1995.

TAIZ, L.; ZEIGER, E. Fisiologia vegetal. 5. ed. Porto Alegre: ArtMed, 2013. 954 p.

UNESCO, Organização das Nações Unidas para a Educação, a Ciência e a Cultura. Água e Emprego fatos e números. Relatório Mundial das Nações Unidas sobre Desenvolvimento dos Recursos Hídricos 2016. 